\title{
Exploring the Determinants of Polypharmacy Prescribing and Dispensing Behaviours in Primary Care for the Elderly-Protocol for a Qualitative Study
}

\author{
Najwa Taghy ${ }^{1, *}$, Linda Cambon ${ }^{2} \mathbb{D}$, Caroline Boulliat ${ }^{3}$, Olivier Aromatario ${ }^{2}\left(\mathbb{D}\right.$ and Claude Dussart ${ }^{4}(\mathbb{D}$ \\ 1 Laboratory P2S (Systemic Health Process), University Claude Bernard of Lyon 1, University of Lyon, \\ EA4129 Lyon, France \\ 2 ISPED, U1219 Inserm Center, Bordeaux Population Health, University of Bordeaux, CHU Bordeaux, \\ 33000 Bordeaux, France; linda.cambon@u-bordeaux.fr (L.C.); olivier.aromatario@u-bordeaux.fr (O.A.) \\ 3 HIA Desgenettes, Pharmacy, 69000 Lyon, France; caroline.boulliat@intradef.gouv.fr \\ 4 Lyon Public Hospices, Central Pharmacy, Laboratory P2S (Systemic Health Process), University Claude \\ Bernard Lyon 1, University of Lyon, EA4129 Lyon, France; claude.dussart@univ-lyon1.fr \\ * Correspondence: najwa.taghy@gmail.com
}

\section{check for}

updates

Citation: Taghy, N.; Cambon, L.; Boulliat, C.; Aromatario, O.; Dussart, C. Exploring the Determinants of Polypharmacy Prescribing and Dispensing Behaviours in Primary Care for the Elderly-Protocol for a Qualitative Study. Int. J. Environ. Res. Public Health 2021, 18, 7656.

https://doi.org/10.3390/ ijerph18147656

Academic Editor: Paul B. Tchounwou

Received: 1 June 2021

Accepted: 16 July 2021

Published: 19 July 2021

Publisher's Note: MDPI stays neutral with regard to jurisdictional claims in published maps and institutional affiliations.

Copyright: (c) 2021 by the authors. Licensee MDPI, Basel, Switzerland. This article is an open access article distributed under the terms and conditions of the Creative Commons Attribution (CC BY) license (https:// creativecommons.org/licenses/by/ $4.0 /)$.

\begin{abstract}
Polypharmacy is becoming increasingly common, especially among the elderly. It often has a negative connotation, but is sometimes necessary or even desirable, and needed to categorize polypharmacy as appropriate or inappropriate. The challenge is in ensuring that this is considered appropriate when necessary. We aimed to develop an evidence-based intervention to reduce the risks associated with using a systematic approach, involving key stakeholders in prescribing and dispensing drugs to the elderly in primary care. The purpose of this study is to identify the key components which are perceived as influencing these behaviours. It is a qualitative study of general practitioners (GPS) and community pharmacists involved in the care of the elderly. The main inclusion criterion is the geographic location. Qualitative data will be generated from one-on-one, semi-structured interviews and processed for thematic content analysis. Our approach integrates the patient pathway in primary care. It considers the fact that GP and pharmacist behaviours are far from being independent. This study represents the first step in the process of developing an intervention theory which involves a crossover between data from the literature and the knowledge of experts, allowing us to interrogate hypotheses about the influences and mechanisms associated with prescribing and dispensing drugs to the elderly in primary care.
\end{abstract}

Keywords: polypharmacy; aging; qualitative study; intervention; prescribing; dispensing; theoretical domains framework

\section{Introduction}

The use of medications is increasing, especially among the elderly. This increase is mainly attributed to the high prevalence of multi-morbidity, with $50 \%$ of adults aged 75 and older now living with at least three concomitant conditions [1] and the broadening of therapeutic options, with an increasing number of clinical practice recommendations calling for the use of more than one drug in the management of chronic diseases [2-4]. Polypharmacy has been identified as the main determinant of potentially inappropriate prescribing among the elderly. It is associated with many negative clinical consequences caused by adverse drug events, but also with the decreased efficacy of treatments or a decreased adherence to treatments. Polypharmacy also has economic implications, including the cost of reimbursing potentially ineffective treatments and the cost of cascading complications $[5,6]$.

There is no universally accepted definition of the term "polypharmacy". Much of the literature to date has referred to numerical thresholds, such as the concomitant prescription of four or five drugs. However, recent studies have highlighted the need to take the clinical 
context in which drugs are prescribed into account. Therefore, the concept of inappropriate use of multiple medications should be preferred over the existing threshold-based definitions [7]. Appropriate polypharmacy is defined as "prescribing for individuals with complex or multiple conditions where drug use has been optimized and prescribing is consistent with the best available evidence". The concept of "inappropriate multiple medications", therefore, recognizes that patients can benefit from multiple medications if the prescription is evidence-based and reflects the clinical needs of the patient [5]. However, these definitions are still based on relatively imprecise concepts, such as "evidence-based" or "clinical needs". A recent review identifies studies the literature that have defined appropriate or rational polypharmacy, or have recognized the distinction between appropriate and inappropriate medications [8]. These studies either defined polypharmacy using a brief description only, or used a brief description and polypharmacy tools, such as the Beers criteria and the Medication Appropriateness Index (MAI) [9-14]. Nevertheless, none of these definitions explicitly allow us to identify any list of behaviours classified as 'inappropriate' in terms of prescribing and dispensing drugs. Therefore, to achieve appropriate medication for the elderly, our approach must be multidimensional. This requires the merging of different disciplines because inappropriate polypharmacy is the result of the combination of several factors, which go far beyond the drug's appropriateness [15].

Our hypothesis is that, in these complex situations, an intervention targeting the main determinants of inappropriate polypharmacy could reduce the associated risks. As such, we chose to investigate the types of approach that could improve the process of prescribing and dispensing medication for the elderly when their state requires more than one medication to be taken. We are specifically interested in the behaviour of general practitioners (GPs) and pharmacists, who, as primary health care providers, are poised to play a pivotal role mitigating this growing issue.

In France, both GPs and community pharmacists are considered as primary care providers. Since 2005, GPs have been given a soft gatekeeper role. Patients must designate a médecin traitant, who is a GP in the vast majority of cases [16-18]. Said GP will be their first point of contact with the health care system. He/she provides referrals to other health professionals (i.e., specialist doctors, providing ambulatory and hospital-based care) and seeks to develop a person-centered approach, ensuring continuous and long-term care [19]. Community pharmacists dispense medication and provide advice. As of March of 2018, community pharmacists have been mandated to support elderly people who are prescribed multiple medications, in close collaboration with GPs. The implementation of "Bilan partagé de médication", which consists of a structured critical analysis of the patient's medications with the objective of establishing a consensus with the patient regarding his or her treatment, taking care to optimize the clinical impact of the medications, reduce the number of problems related to the therapy, and reduce unnecessary extra costs, has truly formalized the shared follow-up of the elderly [20,21].

The research protocol described within is part of a broader research project with the aim of designing and developing an evidence-based, and inherently complex, intervention to reduce the risks associated with inappropriate polypharmacy. Our research project is organized in several phases. The purpose of this one is to develop a theory-based intervention using a systematic approach guided by the best available evidence and appropriate theory, and involving key stakeholders involved in prescribing and dispensing drugs to elderly patients in primary care (i.e., GPs and community pharmacists). The aim of this specific study is to identify and select the key components (mechanisms and activities) perceived as influencing the prescription and dispensing of appropriate polypharmacy.

\section{Materials and Methods}

\subsection{The Underlying Theoretical Model}

Public health, as well as other disciplines, has grasped the concept of complexity. This consideration, more instrumental than conceptual, of this notion in the field of health extends to the design and evaluation of so-called complex interventions. They are complex 
because they are supposed to act on behaviours that cannot be dissociated from their contexts or the systems to which they belong [22]. The Medical Research Council (MRC) emphasizes, according to the same principle, that an intervention is made up of several components that interact with each other and the context in which they take place. The MRC proposes the use of theory-based approaches for the evaluation and development of interventions [23-25].

Our approach has been modelled on these recommendations, and the underlying theoretical model is the theoretical domains framework (TDF). The TDF is founded in the psychological theory of behaviour change. By simplifying these concepts, researchers from non-health-psychology backgrounds can access behavioural theories [26]. Two versions exist: one with 12 theoretical domains and a second, more recent, and refined version with 14 domains [27]. In the appendix (i.e., Appendix A), a flow chart illustrates the two different versions of TDF. The first version of the TDF remains the most widely used version. This is the one we have chosen for our study [28-31]. Thus, the 12 theoretical domains that make up the TDF ( $\mathrm{v} 1.0)$ and are relevant to changing behavioural health care professionals are: knowledge; skills; social/professional role and identity; beliefs about capabilities; beliefs about consequences; motivation and goals; memory, attention and decision processes; environmental context and resources; social influences; emotion; behavioural regulation; nature of the behaviours [26]. For our intervention on targeting prescribing and dispensing behaviour, the TDF v 1.0 will be used to identify key theoretical domains (mechanisms of interactions) that are perceived to influence providers' behaviours and provide a solid evidence base to guide the intervention design. The key components will then be correlated with the behaviour change techniques (BCTs) that may form the "active ingredients" of the intervention (activities) using the S. Michie taxonomy [32].

\subsection{Study Design}

This is a qualitative study. Data will be collected through individual semi-directive interviews. This method of data collection is used to collect information from individuals about their own practices, beliefs, or opinions, to gather information on past or present behaviours or experiences and to tap into the expert knowledge of an individual. These interviews will likely gather factual material and data, such as descriptions of processes [33].

Individual semi-structured interviews also allow professionals the freedom to express their views on their own terms. It is also an appropriate data collection method when seeking to explore the perception and representation of GPs and pharmacists regarding polypharmacy use in the elderly, where our analysis will aim to explore their approaches to prescribing and dispensing polypharmacy in this age group, and their perceptions of barriers and facilitators to achieving appropriate polypharmacy in elderly patients in ambulatory care.

Semi-directive interview guides based on the 12 domains of the TDF will be used. Open-ended questions will be favored, in order to obtain individualized answers while ensuring that the themes covering the 12 domains are well addressed. The interviews will be conducted by the doctoral student (NT). Interviews will be recorded and then transcribed into a text file. An analysis of qualitative data will be carried out in collaboration with other members of the research team.

Data collection for this study commenced in November 2020, and analyses are planned to be completed by the end of July 2021.

\subsection{Constitution of the Panel}

With the objective of understanding reality, our goal is not to establish a representative sample, but rather to identify individuals who possess relevant characteristics that allow us to explore the aspects of the studied phenomenon in depth [34].

The representation that interests us in this qualitative study is a representation of the perspectives, meanings, opinions and ideas of general practitioners and pharmacists with regard to the subject under study. The selected panel does not concern a population 
composed of individuals, but a phenomenon, the lived meaning of which we want to identify [35].

\subsubsection{Selection Criteria}

To serve the objective of our qualitative study, the essential characteristics are, therefore, intentionality and pertinence to our research question [34]. Based on the idea of approaching "competent" GPs and pharmacists, who are likely to provide the most relevant information with regard to our initial questions and to capture the variability in the discourse on the subject under investigation, which is prescribing and dispensing drugs to the elderly in primary care, the main selection criterion was the geographic location of the medical office and pharmacies in which the GPs and pharmacists practice. We aimed to target different geographical areas with a large population of elderly people (aged 60 and over).

\subsubsection{Target Population}

Data from The French National Institute of Statistics and Economic Studies (INSEE) describe the populations of different regions according to age. Nouvelle Aquitaine is the oldest region in France, with $29 \%$ of people aged 60 or over (compared with the national average of 25\%); almost all of these seniors (95\%) live at home [36]. Based on the available INSEE data, seven areas (i.e., Table 1) with an aging population, specifically municipalities where the proportion of the population aged 60 or over exceeds $40 \%$, were targeted [37].

Table 1. Selected Areas in Nouvelle-Aquitaine.

\begin{tabular}{ccc}
\hline Areas & Municipalities & Departments \\
\hline Area 1 & Arcachon & Gironde \\
Area 2 & Soulac-Sur-Mer, Le Verdon, Arès & Gironde \\
Area 3 & Biarritz & Pyrénées-Atlantiques \\
Area 4 & Soorts-Hossegor & Landes \\
Area 5 & Cantons d'Eymet, St-Alvère et Domme & Dordogne \\
Area 6 & Cantons de Lauzun, Villeréal, Castillonnès & Lot-et-Garonne \\
Area 7 & Cantons de Hautefort, Jumilhac-Le-Grand, St-Pardoux-La-Rivière, & Dordogne \\
\hline
\end{tabular}

The constitution of the panel of providers will be conducted in two steps.

\subsubsection{Recruitment of General Practitioners}

GPs were identified in the geographical areas previously defined using the Yellow Pages. Lists will be drawn up and a random selection of doctors to contact will be made. An initial contact will be established by phone. NT will provide potential participants with a brief overview of the study, and answer any questions. Thereafter, an invitation letter and an information sheet with a summary of the project will be sent to those who expressed a wish to receive additional information. Finally, the interviewer (NT) will find the most convenient place and time for a face-to-face interview with the GPs who consented. If necessary, particularly in the context of the COVID-19 epidemic, the interviews may also be conducted over the phone.

\subsubsection{Recruitment of Dispensing Pharmacists}

The choice was made to select pharmacists in a second stage from the network of recruited GPs. In this manner, the recruited physicians will be asked to identify the local pharmacies that dispense most of the prescriptions for elderly patients in the practice. In the same way as for GPs, pharmacists will be contacted by phone by NT, who will provide a brief summary of the project and send additional information to those who have requested it. Appointments will be made, and interviews will be conducted, either in person or over the phone, with consenting pharmacists. 
In all cases, written, informed consent will be obtained from all subjects.

\subsubsection{Panel Size}

An initial panel size is estimated, but the size of the final panel will be determined by data saturation, meaning that no new information or themes emerge from the data and that the interview $n+1$ does not provide anything new compared to the interview $n$ [38-40]. This is implied in the protocol to transcribe and code the interviews as they are conducted. In total, there will be two groups, containing 14-20 GPs (ideally two and at least one from each of the seven zones) and 7-10 pharmacists (at least one from each of the seven zones). This will provide a total panel of 21-30 participants as an initial estimation. However, practical issues such as time or resource constraints, ethical precautions, or accessibility of the professionals to be interviewed may influence the final configuration of our panel.

\subsection{Data Collection}

\subsubsection{Topic Guides}

A first phase of the research project, preceding this survey, consisted of exploring the existing scientific evidence, namely from other countries, and contextual and experiential knowledge about proven or promising interventions related to the issue of inappropriate polypharmacy.

More specifically, a large multi-phase research project has been conducted since 2015 by an Irish team, focusing on the development of interventions using a combination of evidence and theory to address inappropriate polypharmacy in the elderly [28]. One phase of this project resulted in the development of two interview guides based on the 12 domains of TDF, one for GPs (to study prescribing behaviour) and anther one for pharmacists (to study dispensing behaviour). Each topic guide includes a series of similar questions covering four key areas: professionals' views on the term 'polypharmacy'; professionals' assessment of a clinical scenario depicting an older patient receiving inappropriate polypharmacy; professionals' perceptions of barriers and facilitators to ensuring the prescribing (GPs) and dispensing (community pharmacists) of appropriate polypharmacy to older people; professionals' views on potential intervention components and outcome measures for inclusion in future intervention studies. These interview guides were tested, validated, and used during the survey conducted by the Irish research team and published with the results of the survey [41].

Our strategy was to use these guides validated by a researchers' consensus and to adapt them to the needs of the present survey in France. The adaptation of these guides was not limited to translation into French. It also consisted of modifying the questions to be compatible with the context of France. A first version of these two adapted interview guides was elaborated by NT and discussed with the fellow researchers. They were piloted beforehand, during one-on-one interviews with two doctors and two pharmacists who are not part of the sample. If required, questions were reworded, clarified, or completed in order to obtain final versions.

\subsubsection{Interview Process}

NT will conduct semi-structured interviews with recruited professionals either at their place of work, at another convenient location or by phone. Interviews take about $45 \mathrm{~min}$.

A presentation is scheduled at the beginning of each interview and the agreement of the participant will be obtained before starting.

Interviews will be audio-recorded in full using a voice recorder, and additional information will be noted manually. At the end of the interview, an open-ended question will be asked at in order to collect any comments from the participants about the interview process. At the end of the interview, and as soon as possible, non-verbal aspects will be noted, as well as general impressions of the interview process. A verbatim transcript will be made to faithfully reflect the entire content of the interview. The quality of the transcription will be 
checked for each recording. Recordings will be separated into two groups to distinguish the interviews of the doctors from those of the pharmacists, before being anonymized.

\subsection{Analysis}

We will employ thematic content analysis. The process of content analysis allows for the replacement of an intuitive or instinctive interpretation of a given message with a constructed one [42]. More specifically, a thematic analysis will be more conducive to our research because it is about identifying, in the multiform and varied content of an interview, the core of the meanings, to obtain a unique and original analysis of the themes we will have defined beforehand, and possibly specified by professional discourse [43].

NVivo software will be used to facilitate data analysis. There will be a stage where the transcripts are read and reread, without listening to the interview recordings. The transcripts will first be read, checked, and analysed by the NT and another member of the research team, as a validity check, will independently analyse at least $25 \%$ of the transcripts.

A two-step analysis will be adopted. First, a deductive approach using pre-defined coding categories. Second, an inductive approach in which the emerging content themes relating to barriers and facilitators within each domain were identified. The output from the analysis should allow us to identify key theoretical domains and select BCTs.

\subsection{Data Protection and Ethics}

Audio-recordings will be anonymized, with all identifiable information removed prior to using the software analysis tool. All audio-recordings will be destroyed immediately after transcription and the data will be stored on a server at the University of Lyon 1 according to the current standards and conditions. Ethical approval for this study protocol was obtained from the Ethics Committee of the University College of General Medicine (CUMG, University of Lyon, $n^{\circ}$ IRB: 2 July 2020).

\section{Discussion}

Close collaboration between general practitioners and pharmacists in primary care is one of the cornerstones of the multidisciplinary approach, which is recommended in order to optimize the care of the elderly. In France, cooperation between healthcare professionals is a major incentive of the current French national health strategy, "Ma santé 2022", launched in September 2018. Improved collaboration between healthcare providers aims to optimize care pathways, and thus meet the expectations of both patients and providers [44,45]. With regards to the collaboration between GPs and pharmacists, various programs, initiated by the providers or of governmental origin, such as the PAERPA program (Parcours des personnes âgées en risque de perte d'autonomie-care pathways for older people at risk of loss of autonomy), have led to the development of collaborative processes which bring GPs into contact with pharmacists in the context of daily interprofessional communication $[46,47]$. This collaboration is promoted and reinforced by tools such as the medication review (Bilan partagé de médication) which, even more specifically, involves a collaboration between GPs and pharmacists for the management of elderly people experiencing polypharmacy [21]. Although this collaboration remains, in fact, largely informal, we have intended to capitalize on it in the design of this formative research study by deliberately recruiting pharmacists from the network of previously recruited physicians. Although our analysis approach will not take strict physician/pharmacist pairs into account, this recruitment strategy allows for a selection of providers involved in the care, to a certain extent, of the same elderly population. As the two behaviours, prescribing and dispensing drugs, are far from being independent of each other, we have considered the patient pathway in our approach.

\section{Conclusions}

This step of identifying and selecting the key mechanisms perceived to influence the prescribing and dispensing of appropriate polypharmacy is a building block in the process 
of developing an intervention theory targeting these behaviours. This process involves crossing data from the literature and the knowledge of experts (GPs and pharmacists in our case) in a structured approach. The review of the literature can find evidence and define hypotheses. The objective of crossing this with the expertise of professionals is to verify these hypotheses, explaining which components (activities) can influence the targeted behaviours and which mechanisms they use, and to adapt these hypotheses according to the context. The finalized intervention theory (the expected outcome) will consist of an analytical grid composed of $x$ activities (BCTs), which activate $x$ mechanisms influencing the behaviour of GPs (prescription of appropriate polypharmacy for the elderly) and pharmacists (dispensing of appropriate polypharmacy for the elderly).

Author Contributions: N.T., with L.C.'s contribution and under the direction of C.D., designed the protocol, the main conceptual ideas and the study design. N.T. developed the interview topic guides. L.C. provided expertise to help validate the method on the theory-based intervention component and to criticize the interview topic guides. O.A. contributed to critiquing the method and the interview topic guides. C.B. contributed to criticizing the method and discussing the protocol. N.T. wrote the manuscript. All authors contributed to finalising the manuscript, and read and approved the final version. C.D. supervised all the steps involved in elaborating the protocol and the manuscript. All authors have read and agreed to the published version of the manuscript.

Funding: The authors L.C., O.A., C.B., and C.D. received no specific funding for this work. N.T. received funding as part of her PhD for this work by MFP Services (https:/ / www.mfpservices.fr) (accessed on 1 December 2020). This funder had no role in study design, data collection and analysis, decision to publish, or preparation of the manuscript. MFP Services is a public body. It is a union of mutual insurance companies and it manages insurance for civil servants. It is also a health prevention player, financed by the French National Health Insurance Fund (CNAM).

Institutional Review Board Statement: No ethics approval was required for this study. Nevertheless, the protocol was submitted to the advisory opinion of the ethics committee Ethics Committee of the University College of General Medicine (CUMG) which organises the ethics committees for research in general medicine within the University of Lyon. Ethical approval was obtained from the CUMG on 23 July 2020 (n IRB: 2 July 2020).

Informed Consent Statement: Informed consent was obtained from all subjects involved in the study.

Data Availability Statement: This article does not data and the data availability policy is not applicable.

Acknowledgments: The authors would like to thank all the health professionals who agreed to participate in the pre-study phase and who helped to test the interview topic guides. The authors would also like to thank Diana Barger, who kindly agreed to review the manuscript to improve its clarity.

Conflicts of Interest: The authors declare no conflict of interest. The funder had no role in the design of the study; in the collection, analyses, or interpretation of data; in the writing of the manuscript, or in the decision to publish the results. 


\section{Appendix A. The Theoretical Domains Framework (Version1 (19) and Version2 (20)) with Definitions and Component Constructs}

\begin{tabular}{|c|c|c|}
\hline \multirow{13}{*}{ 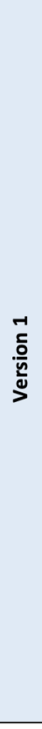 } & Domain & Constructs \\
\hline & Knowledge & Knowledge; Knowledge about condition/scientific rationale; Schemas + mindsets + illness representations; Procedural knowledge \\
\hline & Skills & Skills; Competence/ability/skill assessment; Practice/skills development; Interpersonal skills; Coping strategies \\
\hline & $\begin{array}{l}\text { Social/professional role and } \\
\text { identity }\end{array}$ & $\begin{array}{l}\text { Identity; Professional identity/boundaries/role; Group/social identity; Social/group norms; Alienation/organisational } \\
\text { commitment }\end{array}$ \\
\hline & Beliefs about capabilities & $\begin{array}{l}\text { Self-efficacy; Control-of behaviour and material and social environment; Perceived competence; Self-confidence/professional } \\
\text { confidence; Empowerment; Self-esteem; Perceived behavioural control; Optimism/pessimism }\end{array}$ \\
\hline & Beliefs about consequences & $\begin{array}{l}\text { Outcome expectancies; Anticipated regret; Appraisal/evaluation/review; Consequents; Attitudes; Contingencies; } \\
\text { Reinforcement/punishment/consequences; Incentives/rewards; Beliefs; Unrealistic optimism; Salient events/sensitisation/critical } \\
\text { incidents; Characteristics of outcome expectancies - physical, social, emotional; sanctions/rewards, proximal/distal, valued/not } \\
\text { valued, probable/improbable, salient/not salient, perceived risk/threat }\end{array}$ \\
\hline & Motivation and goals & $\begin{array}{l}\text { Intention; stability of intention/certainty of intention; Goals (autonomous, controlled); Goal target/setting; Goal priority; Intrinsic } \\
\text { motivation; Commitment; Distal and proximal goals; Transtheoretical model and stages of change }\end{array}$ \\
\hline & $\begin{array}{l}\text { Memory, attention and } \\
\text { decision processes }\end{array}$ & Memory; Attention; Attention control; Decision-making \\
\hline & $\begin{array}{l}\text { Environmental context and } \\
\text { resources }\end{array}$ & $\begin{array}{l}\text { Resources/material resources (availability and management); Environmental stressors; Person × environment interaction; } \\
\text { Knowledge of task environment }\end{array}$ \\
\hline & Social influences & $\begin{array}{l}\text { Social support; Social/group norms; Organisational development; Leadership; Team working; Group conformity; Organisational } \\
\text { climate/culture; Social pressure; Power/hierarchy; Professional boundaries/roles; Management commitment; Supervision; Inter- } \\
\text { group conflict; Champions; Social comparisons; Identity; group/social identity; Organisational commitment/alienation; Feedback; } \\
\text { Conflict-competing demands, conflicting roles; Change management; Crew resource management; Negotiation; Social support: } \\
\text { personal/professional/organisational, intra/interpersonal, society/community; Social/group norms: subjective, descriptive, } \\
\text { injunctive norms; Learning and modelling }\end{array}$ \\
\hline & Emotion & $\begin{array}{l}\text { Affect; Stress; Anticipated regret; Fear; Burn-out; Cognitive overload/tiredness; Threat; Positive/negative affect; } \\
\text { Anxiety/depression }\end{array}$ \\
\hline & Behavioural regulation & $\begin{array}{l}\text { Goal/target setting; Implementation intention; Action planning; Self-monitoring; Goal priority; Generating alternatives; Feedback; } \\
\text { Moderators of intention-behaviour gap; Project management; Barriers and facilitators }\end{array}$ \\
\hline & Nature of the behaviours & Routine/automatic/habit; Breaking habit; Direct experience/past behaviour; Representation of tasks; Stages of change model \\
\hline
\end{tabular}

\begin{tabular}{|c|c|c|c|}
\hline \multirow{15}{*}{$\underset{\substack{0 \\
\frac{0}{2}}}{\stackrel{2}{\nu}}$} & Domain & Definition & Constructs \\
\hline & Knowledge & An awareness of the existence of something & $\begin{array}{l}\text { Knowledge (including knowledge of condition/scientific rationale); } \\
\text { Procedural knowledge; Knowledge of task environment }\end{array}$ \\
\hline & Skills & An ability or proficiency acquired through practice & $\begin{array}{l}\text { Skills; Skills development; Competence; Ability; Interpersonal skills; } \\
\text { Practice; Skill assessment }\end{array}$ \\
\hline & $\begin{array}{l}\text { Social/professional } \\
\text { role and identity }\end{array}$ & $\begin{array}{l}\text { A coherent set of behaviours and displayed personal qualities of an } \\
\text { individual in a social or work setting }\end{array}$ & $\begin{array}{l}\text { Professional identity; Professional role; Social identity; Identity; } \\
\text { Professional boundaries; Professional confidence; Group identity; } \\
\text { Leadership; Organisational commitment }\end{array}$ \\
\hline & $\begin{array}{l}\text { Beliefs about } \\
\text { capabilities }\end{array}$ & $\begin{array}{l}\text { Acceptance of the truth, reality or validity about an ability, talent or } \\
\text { facility that a person can put to constructive use }\end{array}$ & $\begin{array}{l}\text { Self-confidence; Perceived competence; Self-efficacy; Perceived } \\
\text { behavioural control; Beliefs; Self-esteem; Empowerment; } \\
\text { Professional confidence }\end{array}$ \\
\hline & Optimism & $\begin{array}{l}\text { The confidence that things will happen for the best or that desired } \\
\text { goals will be attained }\end{array}$ & Optimism; Pessimism; Unrealistic optimism; Identity \\
\hline & $\begin{array}{l}\text { Beliefs about } \\
\text { Consequences }\end{array}$ & $\begin{array}{l}\text { Acceptance of the truth, reality, or validity about outcomes of a } \\
\text { behaviour in a given situation }\end{array}$ & $\begin{array}{l}\text { Beliefs; Outcome expectancies; Characteristics of outcome } \\
\text { expectancies; Anticipated regret; Consequents }\end{array}$ \\
\hline & Reinforcement & $\begin{array}{l}\text { Increasing the probability of a response by arranging a dependent } \\
\text { relationship, or contingency, between the response and a given } \\
\text { stimulus }\end{array}$ & $\begin{array}{l}\text { Rewards (proximal/distal, valued/not valued, probable/improbable); } \\
\text { Incentives; Punishment; Consequents ; Reinforcement ; } \\
\text { Contingencies; Sanctions }\end{array}$ \\
\hline & Intentions & $\begin{array}{l}\text { A conscious decision to perform a behaviour or a resolve to act in a } \\
\text { certain way }\end{array}$ & $\begin{array}{l}\text { Stability of intentions; Stages of change model; Transtheoretical } \\
\text { model and stages of change }\end{array}$ \\
\hline & Goals & $\begin{array}{l}\text { Mental representations of outcomes or end states that an individual } \\
\text { wants to achieve }\end{array}$ & $\begin{array}{l}\text { Goals (distal/proximal); Goal priority; Goal/target setting; Goals } \\
\text { (autonomous/controlled); Action planning; Implementation } \\
\text { intention }\end{array}$ \\
\hline & $\begin{array}{l}\text { Memory, attention } \\
\text { and decision } \\
\text { processes }\end{array}$ & $\begin{array}{l}\text { The ability to retain information, focus selectively on aspects of the } \\
\text { environment and choose between two or more alternatives }\end{array}$ & $\begin{array}{l}\text { Memory; Attention; Attention control; Decision making; Cognitive } \\
\text { overload/tiredness }\end{array}$ \\
\hline & $\begin{array}{l}\text { Environmental } \\
\text { context and } \\
\text { resources }\end{array}$ & $\begin{array}{l}\text { Any circumstance of a person's situation or environment that } \\
\text { discourages or encourages the development of skills and abilities, } \\
\text { independence, social competence and adaptive behaviour }\end{array}$ & $\begin{array}{l}\text { Environmental stressors; Resources/material resources; } \\
\text { Organisational culture/climate } \\
\text { Salient events/critical incidents; Person x environment interaction; } \\
\text { Barriers and facilitators }\end{array}$ \\
\hline & Social influences & $\begin{array}{l}\text { Those interpersonal processes that can cause individuals to change } \\
\text { their thoughts, feelings, or behaviours }\end{array}$ & $\begin{array}{l}\text { Social pressure; Social norms; Group conformity; Social comparisons; } \\
\text { Group norms; Social support; Power; Intergroup conflict; Alienation; } \\
\text { Group identity; Modelling }\end{array}$ \\
\hline & Emotion & $\begin{array}{l}\text { A complex reaction pattern, involving experiential, behavioural, and } \\
\text { physiological elements, by which the individual attempts to deal with } \\
\text { a personally significant matter or event }\end{array}$ & $\begin{array}{l}\text { Fear; Anxiety; Affect; Stress; Depression; Positive/negative affect; } \\
\text { Burn-out }\end{array}$ \\
\hline & $\begin{array}{l}\text { Behavioural } \\
\text { regulation }\end{array}$ & $\begin{array}{l}\text { Anything aimed at managing or changing objectively observed or } \\
\text { measured actions }\end{array}$ & Self-monitoring; Breaking habit; Action planning \\
\hline
\end{tabular}

\section{References}

1. Barnett, K.; Mercer, S.W.; Norbury, M.; Watt, G.; Wyke, S.; Guthrie, B. Epidemiology of multimorbidity and implications for health care, research, and medical education: A cross-sectional study. Lancet 2012, 380, 37-43. [CrossRef]

2. Marengoni, A.; Angleman, S.; Melis, R.; Mangialasche, F.; Karp, A.; Garmen, A.; Meinow, B.; Fratiglioni, L. Aging with multimorbidity: A systematic review of the literature. Ageing Res. Rev. 2011, 10, 430-439. [CrossRef] 
3. Caughey, G.E.; Ramsay, E.N.; Vitry, A.I.; Gilbert, A.L.; Luszcz, M.A.; Ryan, P.; Roughead, E.E. Comorbid chronic diseases, discordant impact on mortality in older people: A 14-year longitudinal population study. J. Epidemiol. Community Health 2010, 64, 1036-1042. [CrossRef] [PubMed]

4. Roughead, E.; Vitry, A.; Caughey, G.; Gilbert, A. Multimorbidity, care complexity and prescribing for the elderly. Aging Health 2011, 7, 695-705. [CrossRef]

5. Duerden, M.; Avery, T.; Payne, R. Polypharmacy and Medicines Optimisation: Making It Safe and Sound; King's Fund: London, UK, 2013.

6. Hovstadius, B.; Petersson, G. The impact of increasing polypharmacy on prescribed drug expenditure-A register-based study in Sweden 2005-2009. Health Policy 2013, 109, 166-174. [CrossRef]

7. Taghy, N.; Cambon, L.; Cohen, J.-M.; Dussart, C. Failure to Reach a Consensus in Polypharmacy Definition: An Obstacle to Measuring Risks and Impacts-Results of a Literature Review. Clin. Risk Manag. 2020, 16, 57-73. [CrossRef] [PubMed]

8. Masnoon, N.; Shakib, S.; Kalisch-Ellett, L.; Caughey, G.E. What is polypharmacy? A systematic review of definitions. BMC Geriatr. 2017, 17, 230. [CrossRef]

9. Bushardt, R.L.; Massey, E.B.; Simpson, T.W.; Ariail, J.C.; Simpson, K.N. Polypharmacy: Misleading, but manageable. Clin. Interv. Aging 2008, 3, 383-389. [CrossRef]

10. Maggiore, R.J.; Gross, C.P.; Hurria, A. Polypharmacy in older adults with cancer. Oncologist 2010, 15, 507-522. [CrossRef] [PubMed]

11. Medeiros-Souza, P.; Santos-Neto LL dos Kusano, L.T.E.; Pereira, M.G. Diagnosis and control of polypharmacy in the elderly. Rev. Saude Publica 2007, 41, 1049-1053. [CrossRef] [PubMed]

12. Fulton, M.M.; Allen, E.R. Polypharmacy in the elderly: A literature review. J. Am. Acad. Nurse Pract. 2005, 17, 123-132. [CrossRef]

13. Cadogan, C.; Ryan, C.; Gormley, G.; Passmore, P.; Francis, J.; Kerse, N.; Hughes, C. Dispensing appropriate polypharmacy to older people in primary care: A qualitative, theory-based study of community pharmacists' perceptions and experiences. 2015, Royal Pharmaceutical Society Annual Conference. Int. J. Pharm. Pract. 2015, 23, 32.

14. Ballentine, N.H. Polypharmacy in the elderly: Maximizing benefit, minimizing harm. Crit. Care Nurs. Q. 2008, 31, 40-45. [CrossRef]

15. Mieiro, L.; Beuscart, J.-B.; Knol, W.; Riet-Nales, D.V.; Orlu, M. Achieving appropriate medication for older adults: A multidimensional perspective. Maturitas 2019, 124, 43-47. [CrossRef]

16. Sous-Section 1: Dispositions Relatives aux Relations Conventionnelles (Articles L162-5 à L162-5-4)—Légifrance. Available online: https: / / www.legifrance.gouv.fr/codes/id/LEGIARTI000036516304/2018-01-19/ (accessed on 1 December 2020).

17. Barnay, T.; Laurence, H.; Philippe, U. Réforme du « Médecin Traitant » et Nouveaux Enjeux de la Médecine de ville en France. PostPrint. HAL. Report No. Halshs-01298642. 2007. Available online: https://ideas.repec.org/p/hal/journl/halshs-01298642.html (accessed on 1 December 2020).

18. Dumontet, M.; Buchmueller, T.; Dourgnon, P.; Jusot, F.; Wittwer, J. Gatekeeping and the Utilization of Physician Services in France: Evidence on the Médecin Traitant Reform. Health Policy 2017, 121, 675-682. [CrossRef]

19. Mezzich, J.; Snaedal, J.; Weel, C.; Botbol, M.; Salloum, I. Introduction to person-centred medicine: From concepts to practice. J. Eval. Clin. Pract. 2010, 17, 330-332. [CrossRef]

20. Arrêté du 9 Mars 2018 Portant Approbation de L'avenant 12 à la Convention Nationale du 4 mai 2012, Organisant les Rapports Entres les Pharmaciens Titulaires D'officine et L'assurance Maladie. Available online: https://www.legifrance.gouv.fr/jorf/id/ JORFTEXT000036711358 (accessed on 1 December 2020).

21. Beillier, A. Le Bilan Partagé de Médication: Un Nouvel Outil Dans la Prise en Charge du Patient Agé et Polymédiqué à L'officine. 2020, 121. Available online: https:/ / dumas.ccsd.cnrs.fr/dumas-02465348/document (accessed on 1 December 2020).

22. Pagani, V.; Kivits, J.; Minary, L.; Cambon, L.; Claudot, F.; Alla, F. La complexité: Concept et enjeux pour les interventions de santé publique. Sante Publique 2017, 29, 31-39. [CrossRef] [PubMed]

23. Campbell, M.; Fitzpatrick, R.; Haines, A.; Kinmonth, A.L.; Sandercock, P.; Spiegelhalter, D.; Tyrer, P. Framework for design and evaluation of complex interventions to improve health. BMJ 2000, 321, 694-696. [CrossRef] [PubMed]

24. Craig, P.; Dieppe, P.; Macintyre, S.; Michie, S.; Nazareth, I.; Petticrew, M. Developing and evaluating complex interventions: The new Medical Research Council guidance. BMJ 2008, 337. Available online: https://www.bmj.com/content/337/bmj.a1655 (accessed on 1 December 2020). [CrossRef] [PubMed]

25. Moore, G.F.; Audrey, S.; Barker, M.; Bond, L.; Bonell, C.; Hardeman, W.; Moore, L.; O'Cathain, A.; Tinati, T.; Wight, D.; et al. Process evaluation of complex interventions: Medical Research Council guidance. BMJ 2015, 350. Available online: https:/ / www.bmj.com/content/350/bmj.h1258 (accessed on 1 December 2020). [CrossRef]

26. Michie, S.; Johnston, M.; Abraham, C.; Lawton, R.; Parker, D.; Walker, A. Making psychological theory useful for implementing evidence based practice: A consensus approach. Qual. Saf. Health Care 2005, 14, 26-33. [CrossRef] [PubMed]

27. Cane, J.; O'Connor, D.; Michie, S. Validation of the theoretical domains framework for use in behaviour change and implementation research. Implement. Sci. 2012, 7, 37. [CrossRef]

28. Cadogan, C.A.; Ryan, C.; Francis, J.J.; Gormley, G.J.; Passmore, P.; Kerse, N.; Hughes, C.M. Development of an intervention to improve appropriate polypharmacy in older people in primary care using a theory-based method. BMC Health Serv. Res. 2016, 16, 661. (accessed on 1 December 2020). [CrossRef] 
29. Murphy, K.; O'Connor, D.A.; Browning, C.J.; French, S.D.; Michie, S.; Francis, J.J.; Russell, G.M.; Workman, B.; Flicker, L.; Eccles, M.P.; et al. Understanding diagnosis and management of dementia and guideline implementation in general practice: A qualitative study using the theoretical domains framework. Implement. Sci. 2014, 9, 31. [CrossRef]

30. Cullinan, S.; Fleming, A.; O’Mahony, D.; Ryan, C.; O'Sullivan, D.; Gallagher, P.; Byrne, S. Doctors' perspectives on the barriers to appropriate prescribing in older hospitalized patients: A qualitative study. Br. J. Clin. Pharmacol. 2015, 79, 860-869. [CrossRef]

31. Mazza, D.; Petrovic, K.; Grech, C.; Harris, N. HPV vaccination in women aged 27 to 45 years: What do general practitioners think? BMC Womens Health 2014, 14, 91. [CrossRef]

32. Michie, S.; Richardson, M.; Johnston, M.; Abraham, C.; Francis, J.; Hardeman, W.; Eccles, M.P.; Cane, J.; Wood, C.E. The behavior change technique taxonomy (v1) of 93 hierarchically clustered techniques: Building an international consensus for the reporting of behavior change interventions. Ann. Behav. Med. Publ. Soc. Behav. Med. 2013, 46, 81-95. [CrossRef] [PubMed]

33. Harrell, M.C.; Bradley, M.A. Data Collection Methods: Semi-Structured Interviews and Focus Groups. 14 December 2009. Available online: https://www.rand.org/pubs/technical_reports/TR718.html (accessed on 1 December 2020).

34. Mays, N.; Pope, C. Rigour and qualitative research. BMJ 1995, 311, 109-112. [CrossRef]

35. Kohn, L.; Christiaens, W. Les méthodes de recherches qualitatives dans la recherche en soins de santé: Apports et croyances. Reflets Perspect Vie Économique 2014, 53, 67. [CrossRef]

36. En Nouvelle-Aquitaine, des Personnes Agées Dépendantes Toujours Plus Nombreuses d'ici 2030-Insee Analyses NouvelleAquitaine 85. 18 June 2020. Available online: https:/ / www.insee.fr/fr/statistiques/4294178 (accessed on 1 December 2020).

37. Les Seniors Aquitains: Davantage en Milieu Rural et sur le Littoral-Insee Flash Aquitaine 1. 18 June 2020. Available online: https: / / www.insee.fr/fr/statistiques/1285344 (accessed on 1 December 2020).

38. Guest, G.; Bunce, A.; Johnson, L. How Many Interviews Are Enough?: An Experiment with Data Saturation and Variability. Field Methods 2006, 18, 59-82. [CrossRef]

39. Marshall, B.; Cardon, P.; Poddar, A.; Fontenot, R. Does Sample Size Matter in Qualitative Research?: A Review of Qualitative Interviews in is Research. J. Comput. Inf. Syst. 2013, 54, 11-22. [CrossRef]

40. Saunders, B.; Sim, J.; Kingstone, T.; Baker, S.; Waterfield, J.; Bartlam, B.; Burroughs, H.; Jinks, C. Saturation in qualitative research: Exploring its conceptualization and operationalization. Qual Quant. 2018, 52, 1893-1907. [CrossRef] [PubMed]

41. Cadogan, C.A.; Ryan, C.; Francis, J.J.; Gormley, G.J.; Passmore, P.; Kerse, N.; Hughes, C.M. Improving appropriate polypharmacy for older people in primary care: Selecting components of an evidence-based intervention to target prescribing and dispensing. Implement. Sci. 2015, 10, 161. [CrossRef]

42. Feller, J. L'Analyse du contenu, de L. Bardin. Commun. Lang. 1977, 35, 123-124.

43. Intissar, S.; Rabeb, C. Étapes à suivre dans une analyse qualitative de données selon trois méthodes d'analyse: La théorisation ancrée de Strauss et Corbin, la méthode d'analyse qualitative de Miles et Huberman et l'analyse thématique de Paillé et Mucchielli, une revue de la littérature. Rev. Fr. Int. Rech. Infirm. 2015, 1, 161-168.

44. Les Protocoles de Coopération Entre Professionnels de Santé. Ministère des Solidarités et de la Santé. Available online: https: / / solidarites-sante.gouv.fr/professionnels / gerer-un-etablissement-de-sante-medico-social/cooperations / cooperationentre-professionnels-de-sante/article/les-protocoles-de-cooperation-entre-professionnels-de-sante (accessed on 1 December 2020).

45. Adoption du Projet de loi Ma Santé 2022 par le Parlement. Ministère des Solidarités et de la Santé. 2020. Available online: https:// solidarites-sante.gouv.fr/actualites/actualites-du-ministere/article/adoption-du-projet-de-loi-ma-sante-2022 -par-le-parlement (accessed on 1 December 2020).

46. La Coopération Interprofessionnelle. Cahier Thématique10.pdf. Available online: http://www.ordre.pharmacien.fr/content/ download/303084/1547370/version/11/file/Cahier+th\%C3\%A9matique+10+-+La+coop\%C3\%A9ration+interprofessionnelle. pdf (accessed on 1 December 2020).

47. Le Parcours Santé des Aînés (Paerpa). Ministère des Solidarités et de la Santé. 2020. Available online: https://solidarites-sante. gouv.fr/systeme-de-sante-et-medico-social/parcours-des-patients-et-des-usagers/le-parcours-sante-des-aines-paerpa/ (accessed on 1 December 2020). 